\title{
Stimulation of pancreatic $\beta$-cell replication by incretins involves transcriptional induction of cyclin D1 via multiple signalling pathways
}

\author{
Birgitte N Friedrichsen, Nicole Neubauer ${ }^{1}$, Ying C Lee ${ }^{1}$, \\ Vivian K Gram , Niels Blume, Jacob S Petersen, Jens H Nielsen ${ }^{1}$ \\ and Annette Møldrup \\ Novo Nordisk A/S, Department of Islet Discovery Research, Krogshoejvej 31, 9R2.28, 2880 Bagsværd, Denmark \\ ${ }^{1}$ The University of Copenhagen, Department of Medical Biochemistry and Genetics, Copenhagen, Denmark \\ (Requests for offprints should be addressed to A Møldrup; Email: amp@novonordisk.com)
}

\begin{abstract}
The incretin hormones, glucagon-like peptide-1 (GLP-1) and glucose-dependent insulinotropic peptide (GIP), have been suggested to act as $\beta$-cell growth factors and may therefore be of critical importance for the maintenance of a proper $\beta$-cell mass. We have investigated the molecular mechanism of incretin-induced $\beta$-cell replication in primary monolayer cultures of newborn rat islet cells. GLP-1, GIP and the long-acting GLP-1 derivative, liraglutide, increased $\beta$-cell replication $50-80 \%$ at $10-$ $100 \mathrm{nM}$ upon a $24 \mathrm{~h}$ stimulus, whereas glucagon at a similar concentration had no significant effect. The stimulatory effect of GLP-1 and GIP was efficiently mimicked by the adenylate cyclase activator, forskolin, at $10 \mathrm{nM}$ ( 90\% increase) and was additive ( $\sim 170-250 \%$ increase) with the growth response to human growth hormone $(\mathrm{hGH})$, indicating the use of distinct intracellular signalling pathways leading to mitosis by incretins and cytokines, respectively. The response to both GLP-1 and GIP was completely blocked by the protein kinase A (PKA) inhibitor, H89. In addition, the phosphoinositol 3-kinase (PI3K) inhibitor wortmannin and the mitogen-activated protein kinase kinase (MEK) inhibitor PD98059, both inhibited GLP-1- and GIP-stimulated proliferation. The p38 mitogen-activated protein kinase (MAPK) inhibitor, SB203580, had no inhibitory effect on either GLP-1
\end{abstract}

or GIP stimulated proliferation. Cyclin Ds act as molecular switches for the G0/G1-S phase transition in many cell types and we have previously demonstrated hGH-induced cyclin D2 expression in the insulinoma cell line, INS-1. GLP-1 time-dependently induced the cyclin D1 mRNA and protein levels in INS-1E, whereas the cyclin D2 levels were unaffected. However, minor effect of GLP-1 stimulation was observed on the cyclin D3 mRNA levels. Transient transfection of a cyclin D1 promoter-luciferase reporter construct into islet monolayer cells or INS-1 cells revealed approximately a $2-3$ fold increase of transcriptional activity in response to GLP-1 and GIP, and a 4-7 fold increase in response to forskolin. However, treatment of either cell type with hGH had no effect on cyclin D1 promoter activity. The stimulation of the cyclin D1 promoter by GLP-1 was inhibited by H89, wortmannin, and PD98059. We conclude that incretin-induced $\beta$-cell replication is dependent on cAMP/PKA, p42 MAPK and PI3K activities, which may involve transcriptional induction of cyclin D1. GLP-1, GIP and liraglutide may have the potential to increase $\beta$-cell replication in humans which would have significant impact on long-term diabetes treatment.

Journal of Endocrinology (2006) 188, 481-492

\section{Introduction}

The intestinal incretin hormones, glucagon-like peptide-1 (7-36) amide (GLP-1) and glucose-dependent insulinotropic peptide (GIP) are released in response to fat and carbohydrate ingestion. Both peptides act to augment glucose-induced insulin secretion from the pancreatic $\beta$-cells and are thus thought to be important for the maintenance of normal glucose tolerance (Holst et al. 1997, Holst 1999). Patients with type 2 diabetes appear to have an impaired incretin effect, and long-acting derivatives of GLP-1 are in clinical development for the treatment of this syndrome (Holst 1999). Further potential advantages of GLP-1 for the treatment of type 2 diabetes are the stimulatory actions on insulin gene expression (Skoglund et al. 2000) and biosynthesis (Fehmann \& Habener 1992), 
and the promotion of $\beta$-cell neogenesis and replication both in vivo and in vitro (Buteau et al. 1999, 2001, Xu et al. 1999, Stoffers et al. 2000, Nielsen et al. 2001). In addition, GIP was also described as a growth factor for the insulinoma cell line, INS-1 (Trümper et al. 2001). The role of incretins as regulators of $\beta$-cell replication (Farilla et al. 2003) and anti-apoptosis that have been recently described (Hui et al. 2003, Urusova et al. 2004, Bregenholt et al. 2005) may be of particular importance since functional $\beta$-cells are progressively lost during development of type 2 diabetes (Bonner-Weir \& Weir 2001).

Both glucagon, GLP-1, and GIP receptors are expressed on pancreatic $\beta$-cells (Moens et al. 1996). The response to these hormones leads to the activation of the adenylate cyclase and the cAMP/protein kinase A (PKA) signalling pathway. Furthermore, GLP-1 and GIP have been reported to stimulate phosphoinositol 3-kinase (PI3K) and p42 mitogen-activated protein kinase (MAPK) activities in insulinoma cells (Frödin et al. 1995, Buteau et al. 1999, Trümper et al. 2001), and up-regulation of the DNA-binding activity of the transcription factor pancreatic and duodenal homeobox gene 1 (PDX-1), has been suggested to play a role in GLP-1 induced DNA-synthesis and regulation of both the insulin gene and genes encoding metabolic enzymes (Buteau et al. 1999). In addition, involvement of $\mathrm{p} 38 \mathrm{MAPK}$ and an atypical protein kinase $\mathrm{C}$ isoform, PKC $\beta$, was demonstrated in GLP-1-induced replication of INS-1 cells (Buteau et al. 2001). Recent experiments indicate that the GLP-1 response in pancreatic $\beta$-cells also involves activation of the epidermal growth factor receptor (EGFR) (Buteau et al. 2003). Thus extensive cross-talk between the G-protein coupled receptor and tyrosine kinase coupled receptor signalling pathways in $\beta$-cells is emerging, as reviewed recently by Brubaker \& Drucker (2004). Therefore, we found it of interest to compare the effects of incretin and growth hormone/prolactin on $\beta$-cell proliferation.

So far most studies on incretin signalling have been conducted with insulinoma cell lines, in particular the INS-1 cell line, which display many features of primary $\beta$-cells, e.g. glucose-dependent insulin secretion (Asfari et al. 1995). However, tumour cell lines are perturbed in their growth regulation and clear interpretations in studies of growth control using these are difficult. In the present study, we have evaluated the contribution of several signalling pathways potentially involved in GLP-1 and GIP-induced $\beta$-cell replication using primary rat $\beta$-cells in monolayer cultures, and compared the effect of the potent $\beta$-cell growth factor, human growth hormone (hGH), acting via the Janus kinase 2/signal transducer and activator of transcription 5 (STAT5) pathway (Friedrichsen et al. 2001). Furthermore, in both primary $\beta$-cells and INS-1E cells, we have investigated the role of GLP-1 and GIP in the regulation of the cell cycle regulatory factors, Cyclin Ds, which are critical for G1 phase progression and S-phase entry in most cell types.

\section{Materials and Methods}

\section{Reagents}

INS-1E cells, kindly provided by Dr C B Wollheim, Geneva, Switzerland, were cultured in RPMI 1640 with Glutamax (Gibco/Invitrogen) supplemented with 10\% heat-inactivated FCS, $100 \mathrm{U} / \mathrm{ml}$ penicillin, $100 \mu \mathrm{g} / \mathrm{ml}$ streptomycin and $50 \mu \mathrm{M} \beta$-mercaptoethanol at $37^{\circ} \mathrm{C}$ in a humidified atmosphere containing $5 \% \mathrm{CO}_{2}$. Cell passages 42-65 were used. GLP-1, liraglutide, exendin (9-39), and hGH (3 IU/mg) were obtained from Novo Nordisk, Bagsværd, Denmark. Glucagon was purchased from Bachem (Bubendorf, Switzerland). Wortmannin, PD98059, SB203580, and H89 were purchased from Calbiochem (La Jolla, CA, USA), and forskolin and bromodeoxyuridine (BrdU) from Sigma-Aldrich. All inhibitors were dissolved in dimethylsulfoxide (Sigma). A monoclonal antibody (M744) to BrdU was obtained from DAKO (Glostrup, Denmark). Guinea pig antiinsulin antiserum was provided by Novo Nordisk. Secondary antibodies were purchased from Jackson ImmunoResearch Laboratories Inc. (West Grove, PA, USA).

\section{Islet isolation and culture}

Pancreatic islets were isolated from 3-5 day-old Wistar rats (Møllegård, Lille Skensved, Denmark) by the collagenase digestion method (Brunstedt et al. 1984). The islets were pre-cultured at $37^{\circ} \mathrm{C}$ for $5-7$ days in bacteriological dishes in RPMI 1640 containing 20 mM HEPES, 100 units $/ \mathrm{ml}$ penicillin, $100 \mathrm{mg} / \mathrm{ml}$ streptomycin and $0.5 \%$ normal human serum (HS). The islets were collected by centrifugation and dispersed by trypsin-EDTA treatment, as previously described in Nielsen et al. (1989). Dispersed islet cells were plated in either $9 \mathrm{~cm}^{2}$ slide flasks (Nunc, Roskilde, Denmark), approximately 100000 cells/flask, for BrdU incorporation assay or in 24-well dishes, approximately 100000 cells/well for transient transfection (see below) in RPMI 1640 supplemented with 2\% HS and $500 \mathrm{ng} / \mathrm{ml} \mathrm{hGH}$. The cells were allowed to attach and spread for 5-7 days before experimentation.

\section{BrdU incorporation assay}

The islet cell monolayers were washed twice in RPMI 1640 containing $2 \%$ HS and pre-cultured for $24 \mathrm{~h}$. The medium was replaced with RPMI 1640 containing 2\% HS and $10 \mu \mathrm{M} \mathrm{BrdU}$, peptides and compounds were added as indicated. Cells were pre-incubated with protein kinase inhibitors for $15 \mathrm{~min}$ prior to hormone addition and the incubation continued for $24 \mathrm{~h}$, after which the slides were washed twice in serum-free medium and the cells fixed in $1 \%$ paraformaldehyde in $0.1 \mathrm{M}$ phosphate buffer, $\mathrm{pH} 7 \cdot 4$. The slides were exposed to $1.5 \mathrm{M} \mathrm{HCl}$ for $1 \mathrm{~h}$ and washed to neutrality. Incubation with $\mathrm{BrdU}$ and 
insulin antibodies was carried out in PBS containing $0 \cdot 3 \%$ Triton X-100 and $0 \cdot 1 \%$ human serum albumin for $1 \cdot 5 \mathrm{~h}$ at room temperature. The antibodies were visualized using Texas-red conjugated goat anti-mouse immunoglobulin $(\operatorname{IgG})$ and fluorescein isothiocyanate-conjugated goat antiguinea pig $\operatorname{IgG}$, respectively. Double-positive cells as a percentage (mitotic index) of the total number of insulinpositive cells counted (1000-2000/slide) were determined by counting under the microscope.

\section{$R N A$ extraction and quantitative $R T-P C R$}

Islets were cultured in suspension in RPMI 1640 containing $0.5 \% \mathrm{HS}$ and stimulated for $24 \mathrm{~h}$. Total RNA was isolated using RNeasy (Qiagen) as described by the protocol of the manufacturer, cDNA was synthesized from $1 \mu \mathrm{g}$ of RNA as previously described (Friedrichsen et al. 2001). Primer sets complementary to cyclin Ds and internal control genes and conditions of RT-PCR were carried out as described previously (Friedrichsen et al. 2001).

INS-1E cells were treated with or without GLP-1 $(100 \mathrm{nM})$ (Novo Nordisk) or forskolin $(10 \mu \mathrm{M})$ (Sigma) for 6 and $12 \mathrm{~h}$. Total RNA was isolated and purified from INS-1E by Trizol reagent (Invitrogen). For the first strand cDNA synthesis, RNA $(0.75 \mu \mathrm{g})$ was reversed-transcribed using RevertAid First Strand cDNA Synthesis Kit (Fermentas Life Sciences, St. Leon-Rot, Germany) with oligo (dT)18 according to manufacturer's instructions. The first strand cDNA obtained was diluted 1:2 and stored at $-20{ }^{\circ} \mathrm{C}$ until use. Quantitative PCR was carried out using the LightCycler (LC) (Roche) with LC FastStart DNA Master ${ }^{\text {PLUS }}$ SYBR Green I (Roche) in a total reaction volume of $10 \mu \mathrm{l}$, containing $2 \mu \mathrm{l}$ of the diluted first strand cDNA. The real-time PCR runs were all performed using the same reaction conditions for denaturation, amplification, and extension (initial activation, $10 \mathrm{~min}$ at $95^{\circ} \mathrm{C}$; followed by $10 \mathrm{~s}$ denaturation at $95^{\circ} \mathrm{C}$, $5 \mathrm{~s}$ annealing at $55^{\circ} \mathrm{C}, 20 \mathrm{~s}$ extension at $72{ }^{\circ} \mathrm{C}$; for 35 to 40 cycles). Gel electrophoresis and/or melting curve analysis were used to confirm the fidelity of the LC PCR products. The oligonucleotide primers used in the PCR were synthesized by Sigma-Genosys Ltd. The primer pairs for cyclin D1, 2, 3 and Ribosomal Protein L13 (RPL13) (the reference gene) were designed based on rat and mouse sequence information. The primers were: cyclin D1 sense TGGCCTCTAAGATGAAGGAGA, antisense AGGAA GTGTTCGATGAAATCGT, (170 bp); cyclin D2 sense CTGCAGAACCTGTTGACTATCG, antisense TAATT CATGGCCAGAGGAAAG, (171 bp); cyclin D3 ATGT CTTCCCTCTGGCTATGAA, antisense GGTCCGT ATAGATGCAGAGCTT, (162 bp); and RPL13 sense CCACCCTATGACAAGAAAAAGC; antisense ACATT CTTTTCTGCCTGTTTCC, (227 bp).

To create the calibration standards for the realtime PCR, PCR fragments generated with the above-mentioned primer pairs using rat islet cDNA as a template together with PCR master mix (Roche) were sub-cloned into pSTBlue-1 vector (pSTBlue-1 AccepTor Vector kit; Novagen, Germany), and identity was confirmed by sequencing. These respective individual PCR fragments containing plasmids were linearised by HindIII, serial-diluted by a factor of 10 , to create a series of diluted PCR fragments bearing plasmid solutions. They were employed as the external calibration standards in real-time PCR, and RPL13 expression was used as the internal reference control for the quantification of relative cyclin D1, 2 and 3 gene expression.

\section{Western blotting}

INS-1E cells were seeded in $30 \mathrm{~mm}$ cell culture dishes $\left(1 \times 10^{6}\right.$ cells per dish $)$ and cultured for two days. Prior to stimulation, the cells were incubated in RPMI 1640 containing $0 \cdot 25 \%$ bovine serum albumin (BSA) overnight and the medium was changed next day to stimulate the cells with $10 \mathrm{nM}$ GLP-1 for 1·5, 3, 6 and $12 \mathrm{~h}$. Samples were harvested by the addition of RIPA lysis buffer (1\% Triton-X 100, $0 \cdot 5 \%$ sodium deoxycholate, $0 \cdot 1 \%$ SDS, $1 \mathrm{mM}$ AEBSF, $1 \mathrm{mM}$ orthovanadate, $1 \mu \mathrm{g} / \mathrm{ml}$ aprotinin, $1 \mu \mathrm{g} / \mathrm{ml}$ leupeptin in PBS) and the lysate was transferred into eppendorf tubes. The lysate was kept on ice for $30 \mathrm{~min}$ to ensure total lysis of the cells and the samples were frozen in liquid nitrogen. The lysate was centrifuged for $3 \mathrm{~min}$ at $1100 \mathrm{~g}$ and the supernatant used to determine total protein content (Bio-Rad protein assay dye reagent). Equal amounts of total protein $(40 \mu \mathrm{g} / \mathrm{lane})$ were separated on a SDS-PAGE (NuPAGE 12\% Bis-Tris Gel; Invitrogen) in running buffer (NuPAGE MOPSSDS). Prior to separation, $4 \times$ sample buffer $($ NuPAGE LDS sample buffer and NuPAGE sample reduction agent; Invitrogen) was added to the samples and denatured by $70{ }^{\circ} \mathrm{C}$ for $10 \mathrm{~min}$. The proteins were transferred to a Invitrolon PVDF membrane using the Novex electrophoresis and blotting system (Invitrogen). The PVDF membrane was blocked by incubation in $5 \%$ skimmed milk in TBS- $\mathrm{T}$ (Tris- $\mathrm{HCl}$ buffered saline containing $0,1 \%$ Tween-20) and protein expression was detected by incubation for $90 \mathrm{~min}$ at RT with the primary antibody (mouse monoclonal anti-cyclin D1, D2 and D3 antibody (1:200); Lab Vision Corporation, USA and rabbit polyclonal anti-Cdk4 (1:500); Santa Cruz Biotechnology, CA, USA) followed by a $1 \mathrm{~h}$ incubation at room temperature with the HRP-conjugated secondary antibody (rabbit anti-mouse IgG, 1:1000; Dako and swine anti-rabbit IgG, 1:1000, Dako; Denmark). Proteins were visualized using enhanced chemoluminiscence (ECL) plus Western blotting detection reagents (RPN2132; Amersham Biosciences). The blot was stripped using Restore Western Blot Stripping Buffer (Pierce, Rockford, IL, USA). 


\section{Transient transfection}

A firefly luciferase reporter construct containing $2.4 \mathrm{~kb}$ of the mouse cyclin D1 promoter (kindly provided by Dr Martin Eilers, University of Marburg, Marburg, Germany) along with the internal control plasmid TKrenilla (Promega) were transiently transfected into islet monolayer or INS-1E cells using LipofectAMINE 2000 (Invitrogen Life Technologies) as previously described (Friedrichsen et al. 2003) using $2 \mu$ l Lipofect AMINE 2000/well. Islet and INS-1E cells were incubated overnight with DNA-lipofectamine-Optimem mix in RPMI 1640 containing $2 \%$ HS and Optimem, respectively. The media were replaced for islet cells with RPMI 1640 containing 2\% HS and for INS-1E cells with RPMI 1640 containing $0 \cdot 25 \% \mathrm{BSA}$ and $50 \mu \mathrm{M} \beta$-mercaptoethanol, incubation continued for $24 \mathrm{~h}$ in the presence of compounds as indicated. Luciferase reporter assay was performed as previously described (Galsgaard et al. 1999, Friedrichsen et al. 2003).

\section{Results}

Effect of GLP-1, liraglutide, GIP and glucagon on $\beta$-cell replication in vitro

Monolayer cultures of pancreatic islet cells were stimulated with GLP-1, liraglutide, GIP and glucagon in a concentration range of $0 \cdot 1-100 \mathrm{nM}$ for $24 \mathrm{~h}$. DNA synthesis of the $\beta$-cells measured by incorporation of BrdU followed by immunocytochemical staining for insulin and BrdU was carried out as previously described (Nielsen et al. 1989). GLP-1, liraglutide and GIP significantly increased the mitotic index from a basal level of approximately $3-4 \%$ to $5-7 \%$ fold at a maximal stimulatory concentration of 10-100 nM (Fig. 1). Co-incubation of GLP-1 and liraglutide with the GLP-1 receptor antagonist, exendin (9-39) completely inhibited the effect of both peptides, indicating that the effect of liraglutide as expected is mediated by the GLP-1 receptor. Incubation with $0 \cdot 1-100 \mathrm{nM}$ of glucagon had no significant effect on replication of the $\beta$-cells in these cultures. Co-incubation of GLP-1 $(100 \mathrm{nM})$ or GIP $(100 \mathrm{nM})$ with hGH $(0.5 \mu \mathrm{g} / \mathrm{ml})$ for $24 \mathrm{~h}$ had an additive/synergistic effect on $\beta$-cell replication (Fig. 2A). Treatment with hGH led to an approximate $120 \%$ increase of mitotic activity after $24 \mathrm{~h}$, while GLP-1 and GIP instigated an approximate $50 \%$ increase. Combination of hGH and GLP-1 led to a $170 \%$ increase of BrdU-positive $\beta$-cells (indicating an additive effect), while co-incubation of GIP with hGH produced an approximate $250 \%$ increase (suggesting a synergistic effect). The effect of GIP and hGH in combination produced a mitotic index of up to approximately 20\% (Fig. 2B).

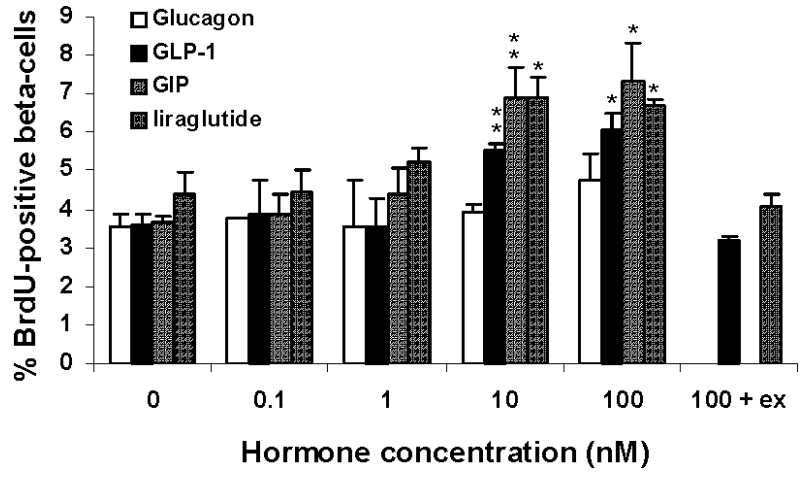

Figure 1 Effect of glucagon, GLP-1, GIP and liraglutide, on $\beta$-cell replication. Dispersed islet cells in monolayer culture were stimulated with peptides, as indicated, for $24 \mathrm{~h}$ in the presence of $10 \mu \mathrm{M}$ BrdU. BrdU-positive $\beta$-cells were visualized by double-immunostaining for insulin and BrdU and quantified by counting under the microscope. The mitotic index was calculated as the fraction of BrdU-positive $\beta$-cells in percent of the total number of $\beta$-cells counted (1000-2000/slide). Data represented are means \pm S.E.M. $(n=3-6)$. Asterisks indicate statistically significant differences ( $t$-test, unpaired) between cells cultured in the absence and presence of the indicated peptides. ${ }^{*} P<0 \cdot 05 ;{ }^{*} P<0 \cdot 01$. Ex, exendin (9-39).

Effect of protein kinase inhibitors on GLP-1 and GIP-induced $\beta$-cell replication

The islet cell monolayer cultures were incubated with GLP-1 $(100 \mathrm{nM})$ or GIP $(100 \mathrm{nM})$ in the presence of the PKA inhibitor, H89 $(10 \mu \mathrm{M})$, the PI3K inhibitor, wortmannin $(10 \mathrm{nM})$, the MEK inhibitor, PD98059 $(20 \mu \mathrm{M})$, and the p38 MAPK inhibitor, SB203580 $(10 \mu \mathrm{M})$ and the effect of these kinase inhibitors on $\beta$-cell replication was measured by BrdU incorporation assay (Fig. 3). The $\beta$-cell mitotic response to both GLP-1 and GIP was completely inhibited by H89. In addition, GLP-1-stimulated proliferation was completely inhibited by wortmannin and GIP-stimulated DNA synthesis was blocked by PD98059. A tendency for the inhibition of GLP-1-stimulated DNAsynthesis by PD 98059 and GIP-stimulated DNA-synthesis by wortmannin was also observed. No inhibitory activity was observed by co-incubation with SB203580 on either GLP-1 or GIP-stimulated activity. As previously reported, wortmannin and PD98059 have no inhibitory effect on hGH-stimulated $\beta$-cell replication in this assay and neither of the various inhibitors significantly affected the basal mitotic rate at the concentrations used (data not shown, described previously in Friedrichsen et al. 2001). The adenylate cyclase activator forskolin $(10 \mu \mathrm{M})$ instigated an increase of $\beta$-cell replication similar to GLP-1 and GIP, indicating that elevation of cAMP is a sufficient stimulus to initiate mitosis of pancreatic $\beta$-cells.

\section{Analysis of GLP-1 induced cyclin D expression}

To determine whether induction of the cell cycle regulatory factors, cyclin Ds, may be involved in the mitotic 

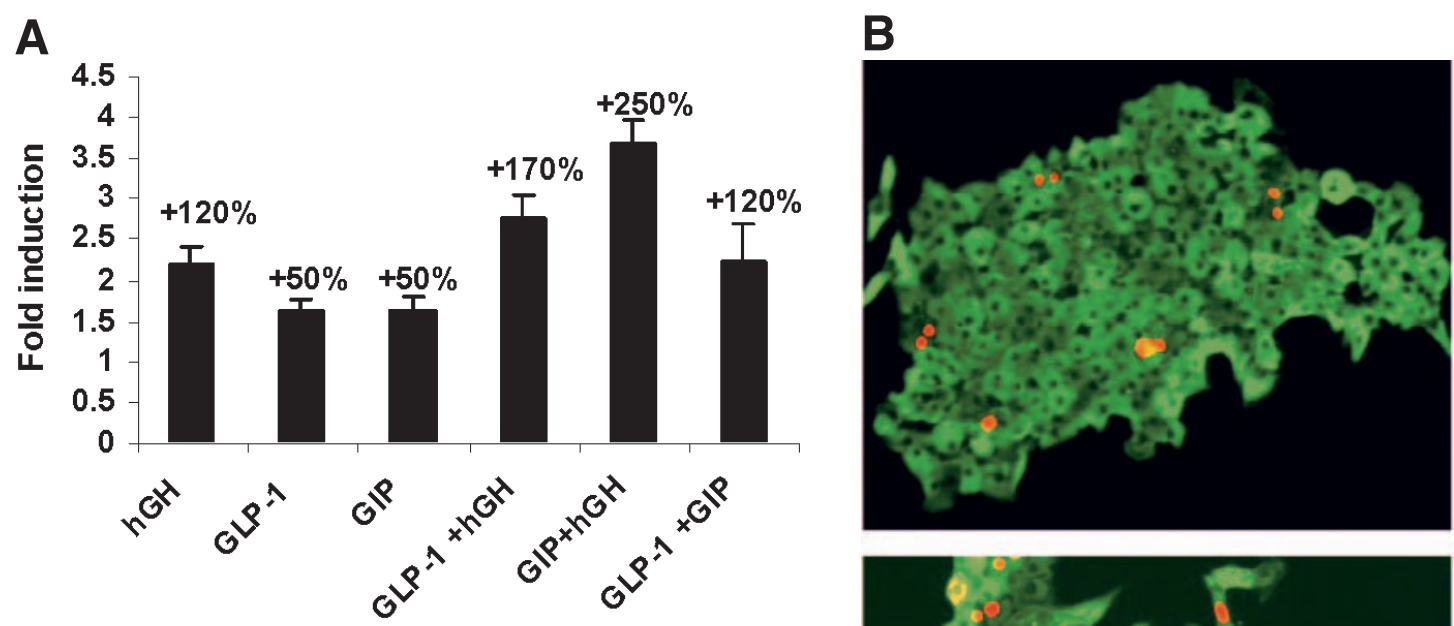

\section{Control}

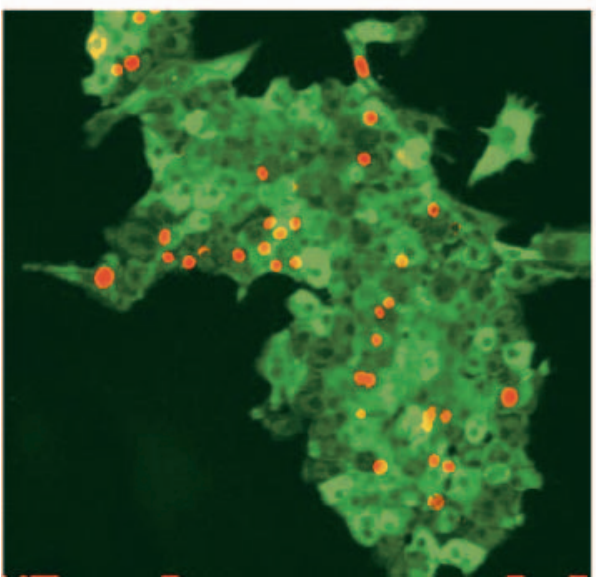

\section{hGH+} GIP

Figure 2 Effect of combinatorial treatment with hGH, GLP-1, and GIP on $\beta$-cell replication. Islet cell monolayer cultures were stimulated with peptides as indicated and $\beta$-cell replication was measured as described in Fig. 1. The basal BrdU incorporation range was $3 \cdot 8 \pm 0 \cdot 1$ percent BrdU-positive beta-cells. (A) Quantified data representing means \pm S.E.M. of 3-5 independent experiments. (B) A representative of the observed effect of the combination of hGH and GIP.

response to GLP-1, newborn rat islets were stimulated for $24 \mathrm{~h}$ with hGH, GLP-1 and forskolin and the mRNA levels of cyclin D1, D2, and D3 were determined by quantitative RT-PCR (Fig. 4). As previously demonstrated in INS-1 cells, we observed in primary islets a significant increase (approximately $80 \%$ ) of cyclin D2 mRNA levels in response to hGH treatment whereas hGH had no effect on cyclin D1 and D3 mRNA levels. In contrast, we found a statistically significant effect of forskolin on cyclin D1 expression and a $\sim 1.4$ fold increase of cyclin D1 expression in response to GLP-1 stimulation, which was not found to be statistically significant. GLP-1 is a weaker growth stimulus islet cells compared with hGH. Forskolin appears, based on the reporter assay analysis, to be a more potent inducer of the cyclin D1 promoter than GLP-1. We would therefore anticipate a smaller induction of cyclin D1 mRNA expression by GLP-1 than forskolin.

Additionally, INS-1E cells were stimulated for 6 and $12 \mathrm{~h}$ with GLP-1 and the mRNA levels of cyclin D1, D2, and D3 were determined by quantitative RT-PCR (Fig. $5 \mathrm{~A}$, left panel). The cyclin D1 mRNA level was significantly increased by GLP-1 with an increase of 100 and $37 \%$ over their respective basal levels at 6 and $12 \mathrm{~h}$. GLP-1 had a minor but significant effect on cyclin D3 expression at these time points, 20 and $28 \%$ over their basal levels, respectively. The cyclin D2 level was not affected by GLP-1 stimulation. The same effects were obtained with forskolin stimulation, however the inductions were more marked (Fig. 5A, right panel). Cyclin D1 expression was induced 900 and $400 \%$ over their respective controls at 6 and $12 \mathrm{~h}$, respectively and cyclin D3 was induced 150 and $110 \%$, respectively, at these two time points. Forskolin had no effect on cyclin D2. At the protein level, cyclin D1 was induced by GLP-1 in a time-dependent manner with maximal induction after $12 \mathrm{~h}$ (Fig. 5B). However, the cyclin D2 and D3 levels were not affected by GLP-1 at any time points. Furthermore, we investigated the catalytic subunit of cyclin D, CDK4, and found that it was neither affected by GLP-1. 


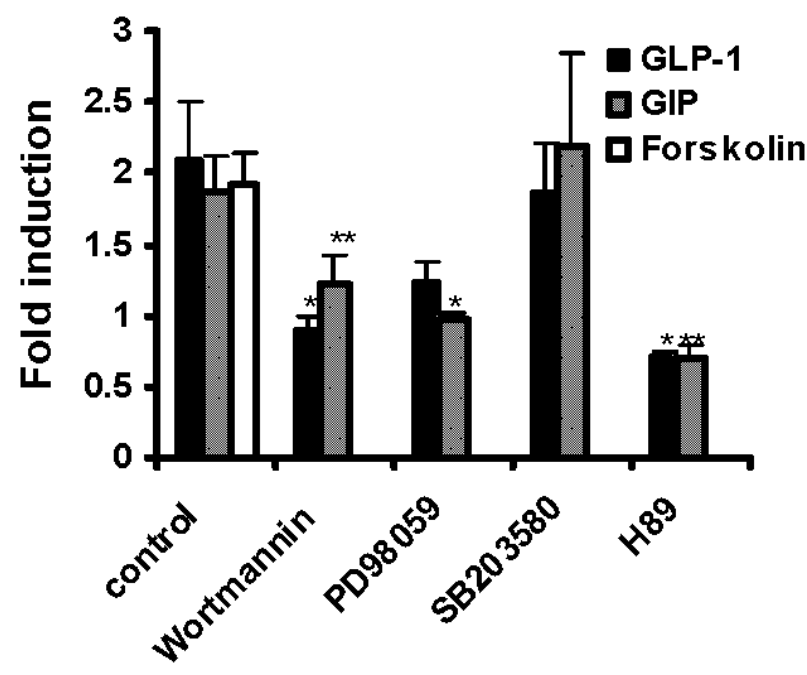

Figure 3 Effect of protein kinase inhibitors on GLP-1 and GIP induced $\beta$-cell replication. Islet cell monolayer cultures were pre-treated with protein kinase inhibitors for 10-15 min, stimulated for $24 \mathrm{~h}$ with GLP-1 (100 nM) or GIP (100 nM) in the presence of $\mathrm{BrdU}$, and $\mathrm{BrdU}$ incorporation measured as described in Fig. 1. Quantified data represent the means \pm S.E.M. of 3-7

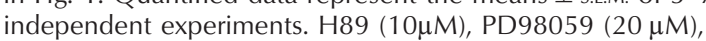
SB203590 $(10 \mu \mathrm{M})$, wortmannin $(10 \mathrm{nM})$, forskolin $(10 \mu \mathrm{M})$. Asterisks indicate statistically significant differences ( $t$-test, unpaired) between cells cultured in the absence and presence of the indicated inhibitors. ${ }^{*} P<0 \cdot 05 ;{ }^{* *} P<0 \cdot 01$.

\section{Transactivation of the cyclin D1 promoter by GLP-1}

To further address the role of GLP-1 and potentially other cAMP-elevating hormones in the transcriptional control of the cyclin D1 gene in pancreatic $\beta$-cells, we performed reporter gene analysis using a $2.4 \mathrm{~kb}$ promoter fragment of the cyclin D1 gene coupled to a cDNA encoding firefly luciferase. Upon stimulation of islet cells, transiently transfected with this construct, we observed a $2 \cdot 5$-fold increase of promoter activity in response to GLP-1 treatment and a 6-8-fold increase of promoter activity in response to forskolin (Fig. 6A). Stimulation with hGH had no effect on cyclin D1 promoter activity, and neither GLP-1, hGH nor forskolin affected the activity of the promoter-less reporter vector, pGL2-b. Effects on cyclin D1 promoter activity similar to those produced by GLP1 have been observed with GIP in these islet cell cultures (data not shown). Transient transfection of the reporter construct into INS-1E cells followed by stimulation with

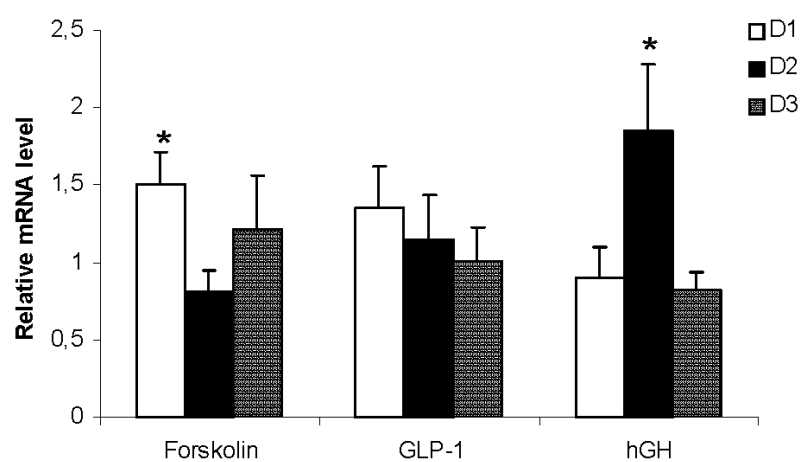

Figure 4 Effect of GLP-1 on cyclin D mRNA in newborn rats. Islets were cultured in suspension in the absence or presence of GLP-1, hGH, and forskolin, as indicated, for $24 \mathrm{~h}$. The islets were harvested, RNA extracted and quantitative RT-PCR analysis performed using primer sets specific for cyclin D1, D2, and D3, respectively, and using primer sets specific for tata-binding protein (TBP) and glucose 6-phospate dehydrogenase (G6 PDH) as internal controls. Data represented (means \pm S.D. of 3 independent cDNA preparations) shows the calculated relative mRNA levels where the basal expression is assigned $1 \cdot 0$. Asterisks indicate statistically significant differences ( $t$-test, unpaired) between cells cultured in the absence and presence of the indicated treatment. ${ }^{*} P<0 \cdot 05$.

hGH, GLP-1, GIP or forskolin produced similar effects as in islet cells. Thus, GLP-1, GIP and forskolin specifically increased cyclin D1 promoter activity approximately 1.5 , 2 , and 4-fold respectively, whereas no effect of hGH was observed (Fig. 6B).

\section{Effect of protein kinase inhibitors on GLP-1-induced cyclin D1 promoter activity}

In order to initially characterize the signalling pathways and transcription factors that may be involved in GLP-1and cAMP-induced transcriptional activation of the cyclin D1 promoter, protein kinase inhibitors were co-incubated with GLP-1 and forskolin in the cyclin D1 promoterreporter assay (Fig. 7). The PKA inhibitor, H89, the PI3K inhibitor, wortmannin, and the MEK inhibitor, PD98059, all inhibited GLP-1-induced activation of the cyclin D1 promoter, whereas the p38 MAPK inhibitor, SB203580 had no effect. The same effects of the inhibitors were observed for forskolin-induced cyclin D1 promoter activity (data not shown).

\footnotetext{
Figure 5 Effect of GLP-1 on cyclin D mRNA and protein levels in INS-1E cells. (A) INS-1E cells were grown as monolayer culture in the absence or presence of GLP-1 for 6 and $12 \mathrm{~h}$. The INS-1E cells were harvested, RNA extracted and quantitative PCR analyses of the relative expression of cyclin D1, D2, and D3 mRNA were performed using primer sets specific for cyclin D1, D2, and D3, respectively. The respective mRNA expression levels were relative to RPL13 expression level in the same sample at 6 and 12 h. Data represent mean \pm s.E.M of 6 independent CDNA preparations done in duplicate in the individual PCR run. The cDNA preparations were done in duplicate in the individual PCR run. Open bar is control, filled bar is $100 \mathrm{nM}$ GLP-1 (7-36) and dotted bar is $10 \mu \mathrm{M}$ forskolin (Fsk). The statistical analysis was assessed first by one-way ANOVA, followed by Tukey's multiple comparison test. ${ }^{* * *} P<0 \cdot 001 ;{ }^{* *} P<0 \cdot 01$; ${ }^{* *} P<0 \cdot 05$. (B) INS-1E were stimulated with $10 \mathrm{nM} \mathrm{GLP}-1$ and harvested at the indicated timepoints. Total protein was extracted and Western blot performed using specific antibodies for cyclin D1-D3 and CDK4. Data illustrate a representative of 2 independent experiments.
} 

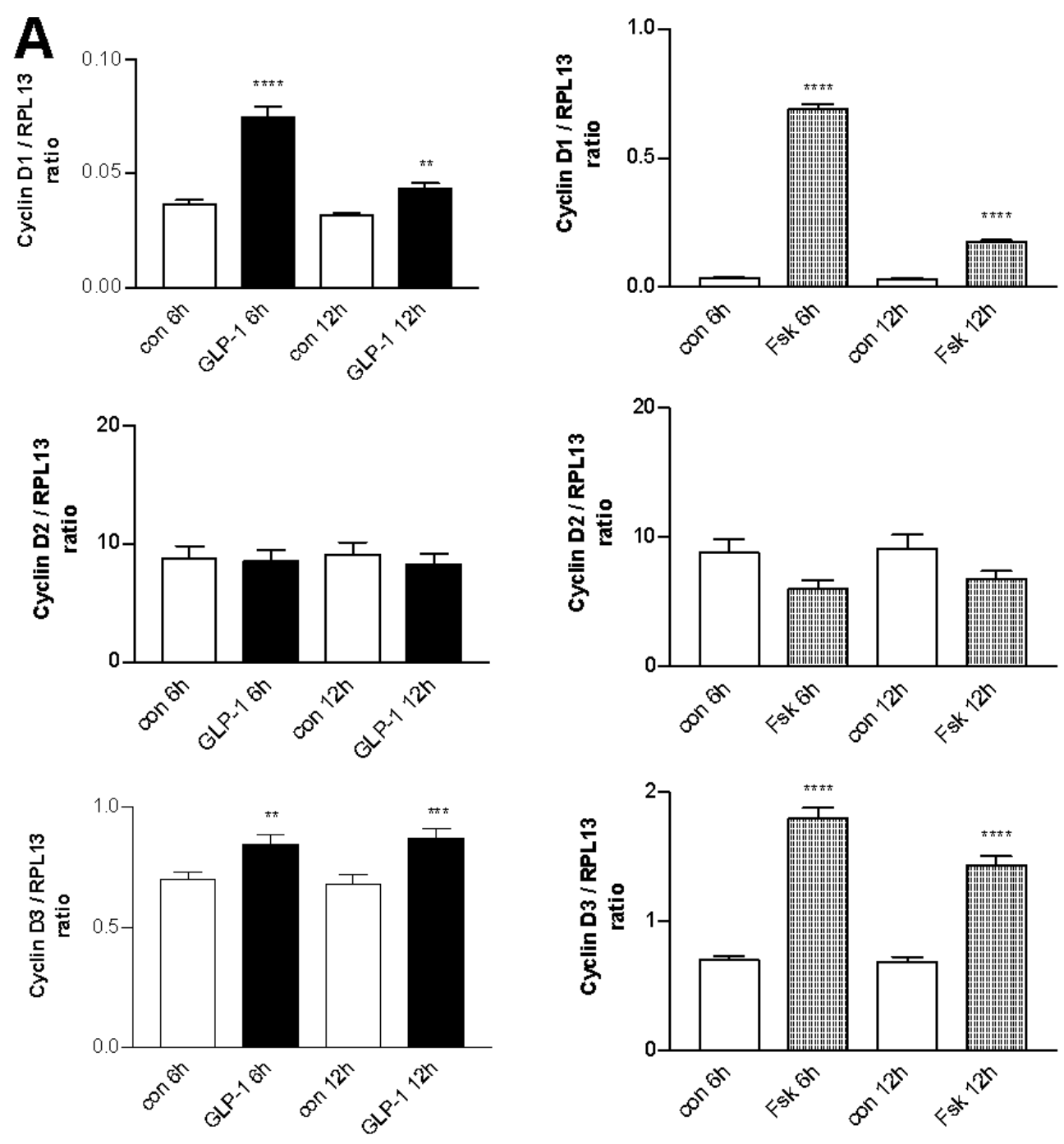

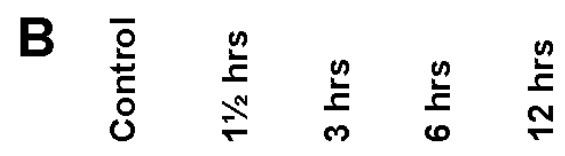

\author{
Cyclin D1
}

\author{
Cyclin D2
}

\title{
Cyclin D3
}

\section{CDK4}



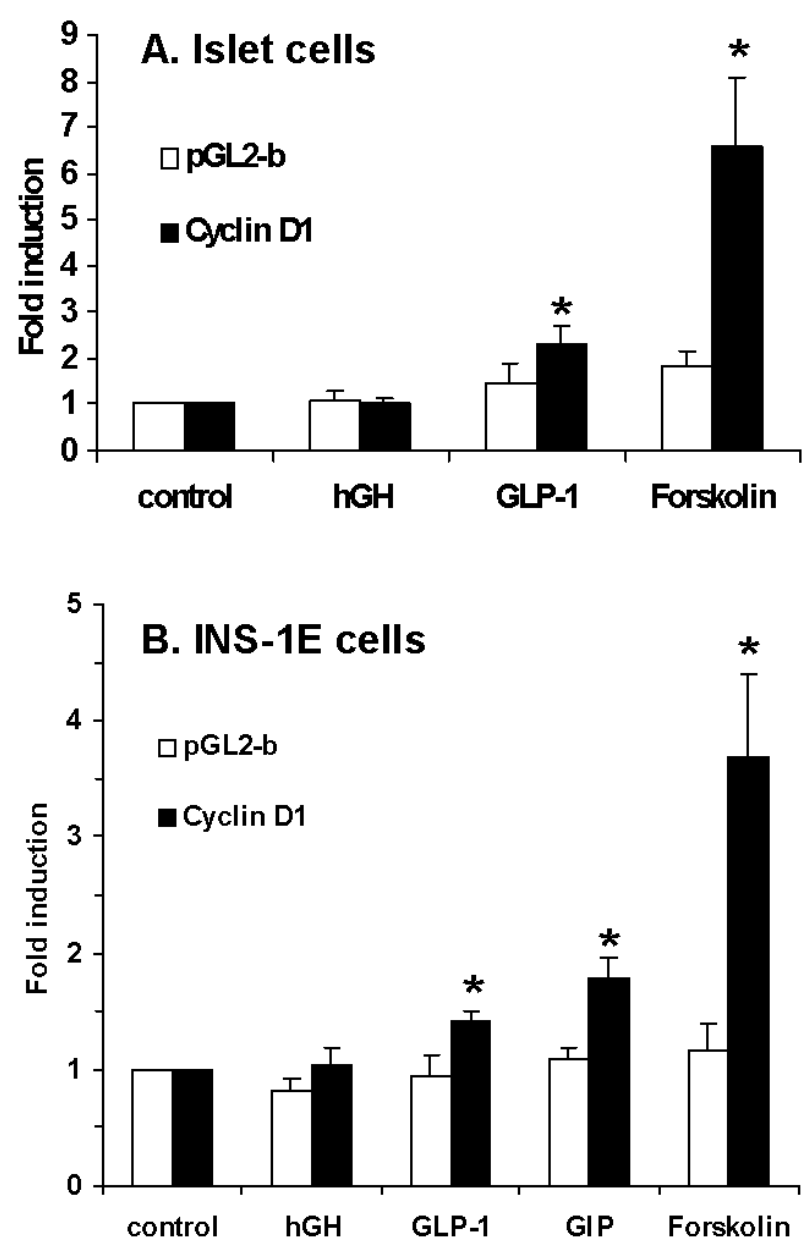

Figure 6 Effect of GLP-1 and GIP on cyclin D1 promoter activity in insulin producing cells. (A) Islet cell monolayer cultures were prepared in 24-well dishes and transfected overnight using LipofectAMINE 2000 with cyclin D1-promoter-luciferase construct or promoter-less luciferase vector (pGL2-b). The transfected cells were stimulated with peptide as indicated for $24 \mathrm{~h}$ and the cells extracted and subjected to analysis of firefly luciferase activity. Data (means \pm S.E.M. of 4-7 independent experiments) are represented as fold induction where the basal activity is assigned a value of $1 \cdot 0$. (B) INS-1E cells transfected and subjected to analysis of peptide-induced cyclin D1 promoter activity as above. Data represented are means \pm S.E.M. of 3-4 independent experiments. Asterisks indicate statistically significant differences ( $t$-test, unpaired) between cells cultured in the absence and presence of the indicated treatment. ${ }^{\star} P<0 \cdot 05$. The internal control plasmid produced in the islet cells activities in the range of 15 000-50 $000 \mathrm{RLU} / 10 \mathrm{~s}$ per $20 \mu \mathrm{l}$ extract, whereas in the INS-1 cells the values ranged from 100 000-800 $000 \mathrm{RLU} / 10 \mathrm{~s}$ per $20 \mu$ l extract.

\section{Discussion}

The differentiated pancreatic $\beta$-cell has generally been considered 'post-mitotic' with very little potential for replication left in the adult organism. However, several

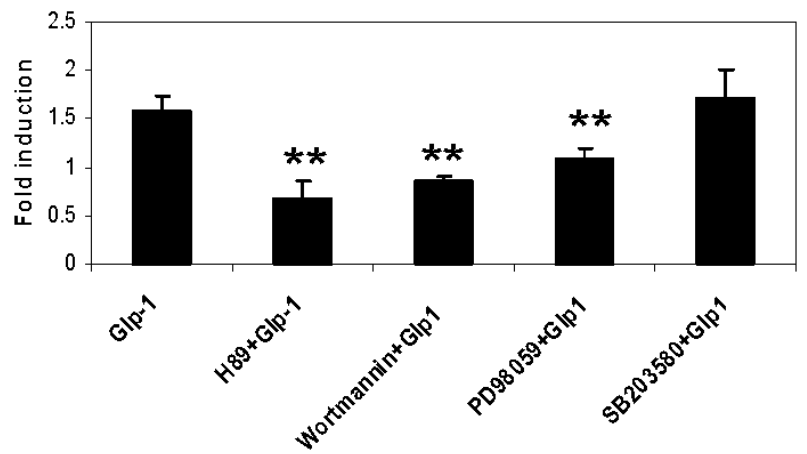

Figure 7 Effect of protein kinase inhibitors on GLP-1 induced cyclin D1 promoter activity. INS-1E cells were transiently transfected as described in Fig. 5 with cyclin D1 promoterluciferase construct and treated with GLP-1 for $24 \mathrm{~h}$ in the absence or presence of protein kinase inhibitors as indicated. Cells were subjected to analysis of luciferase activity and the depicted data (means \pm S.E.M.) shows a single experiment performed with triplicate incubates, representative of 3 independent experiments. Asterisks indicate statistically significant differences ( $t$-test, unpaired) between cells cultured in the absence and presence of the indicated treatment. ${ }^{*} P<0 \cdot 01$.

recent studies indicate that the $\beta$-cell mass is far more plastic than originally thought and that $\beta$-cell replication may occur in response to metabolic demand and certain growth factors and hormones (Eisenbarth \& Stegall 1996, Bonner-Weir \& Weir 2001, Nielsen et al. 2001). In the present study we have shown that GLP-1, GIP, and the long-acting GLP-1 derivative, liraglutide, stimulate $\beta$-cell proliferation in vitro. As expected, the effects of GLP-1 and liraglutide were dependent on the GLP-1 receptor, since a molar excess of exendin 9-39 was able to block the activity of both peptides. In addition, forskolin had a mitogenic effect on the $\beta$-cells indicating that elevation of cAMP levels is sufficient to drive proliferation in these cells in accordance with previous findings (Frödin et al. 1995). Surprisingly, glucagon failed to stimulate $\beta$-cell proliferation in our system. Glucagon receptors have been found to be expressed in rat $\beta$-cells but the activity to stimulate cAMP formation was 45-fold less than that of GLP-1 and GIP receptors (Moens et al. 1996). High concentrations of glucagon will activate GLP-1 receptors (Moens et al. 1998). Interestingly, glucagon but neither GLP-1 nor pituitary adenylyl cyclase-activating peptide were found to stimulate the expression of the transcriptional repressor inducible cAMP early repressor in pancreatic $\beta$-cells (Hussain et al. 2000).

The effects of GLP-1 and GIP on proliferation of the primary $\beta$-cells were found to be dependent on cAMP/ PKA, p42 MAPK and PI3K signalling pathways according to inhibitor experiments, similar to previous studies in insulinoma cell lines (Buteau et al. 1999, Trümper et al. 2001). Our studies indicated some differences in GLP-1 and GIP signalling; GLP-1 signalling seems to be more 
dependent on PI3K activity and this may rely on the recent findings showing that GLP-1 induces transactivation of the EGFR leading to PI3K activation (Buteau et al. 2003). GIP on the other hand appears mostly dependent on p42 MAPK activity, but further studies are needed to clarify this phenomenon. Inhibition of p38 MAPK using SB203580, had no effect on the activities of GLP-1 and GIP, in contrast to a recent study in INS-1 cells (Buteau et al. 2001). Whether this represents a difference between the tumour cell line and primary cells, which we have also observed in relation to growth hormone and prolactin signalling (Friedrichsen et al. 2001), or differences of experimental protocols, awaits to be determined. However, our finding of opposing roles of p42/44 MAPK and p38 MAPK in cell proliferation is similar to findings in other cell types (Lavoie et al. 1996). The stimulatory effect of incretins and hGH on $\beta$-cell replication appeared to be additive in the case of GLP-1 and even synergistic in the case of GIP that also indicates a slight difference in signalling between the two incretins. Although most studies including the knockout of one or both receptors for GLP-1 and GIP suggest a similar mode of action of the two hormones in $\beta$-cells (Preitner et al. 2004) however, subtle differences have been reported. Thus GLP-1 receptors seem to be more prone to desensitization than GIP receptors (Delmeire et al. 2004) and in type 2 diabetes the $\beta$-cell response to GIP is reduced, whereas the response to GLP-1 is retained (Holst \& Gromada 2004).

Exit from the G0 phase of the cell cycle and progression through the so-called restriction point of the G1 phase appears to rely, in most cell types, on transcriptional induction of the cell cycle regulatory factors, cyclin Ds (for review see Reetz et al. 1991, Lania et al. 1999, McDonald \& El Deiry 2000, Garrett 2001). Three cyclin D isoforms exist (D1, D2, D3) encoded by separate genes and with both redundant and non-redundant functions (Fantl et al. 1995, Sicinski et al. 1996, Lahti et al. 1997). Cyclin Ds act as co-factors for cyclin-dependent kinases (cdk) 4 and 6, which are responsible for phosphorylation of retinoblastoma protein and the release of E2F transcription factors, critical for transcriptional induction of many S-phase genes. An important role of these proteins in $\beta$-cell mass regulation is suggested by the finding that Cdk-4 knockout mice carry a diabetic phenotype, whereas knockin of a constitutive active Cdk-4 mutant is associated with $\beta$-cell hyperplasia (Rane et al. 1999).

We have previously demonstrated that $\mathrm{hGH}$, which is a potent growth factor for $\beta$-cells, stimulates the expression of cyclin D2 in INS-1 in a partially STAT5-dependent manner (Friedrichsen et al. 2001). Furthermore, we have recently shown that this up-regulation is mediated by a direct action of STAT5 on the cyclin D2 promoter (Friedrichsen et al. 2003). In the present study, we have investigated the effect of GLP-1 on cyclin D mRNA and protein expression in INS-1E cells, and found that this treatment is associated with a specific elevation of cyclin
D1 in a time-dependent manner with maximal induction at 6 and $12 \mathrm{~h}$, respectively. The reason for the lack of sensitivity in islets compared with the INS-1 cells may be the heterogeneous expression of cyclin D1 and D2s in the $\beta$-cell monolayer cultures (data not shown) which is probably due to 1) lack of synchronization with cell cycle position and/or 2) only a subpopulation of $\beta$-cells responds to growth stimuli by replication within a given time period. In contrast, INS-1 cells can be experimentally synchronized in the cell cycle in low serum and all cells are responsive to growth stimuli. Thus, a low basal mRNA level and high induction rate may be achieved in the cell line compared with the primary cells. No effects were observed on the cyclin D2 and cdk 4 levels. However, a minor effect was detected on the cyclin D3 mRNA levels but no effect was observed at the protein level. Using inhibitors of protein kinases that have been suggested to play a role in $\beta$-cell replication, we found that GLP-1 and GIP-induced $\beta$-cell replication as well as cyclin D1 promoter transcriptional induction were dependent on both cAMP/PKA, PI3K and p 42 MAPK activities.

Both the mouse cyclin D1 and D3 promoter have been found to contain a cAMP regulatory element (CRE) (Wang et al. 1996, Eto 2000). The relatively weak effect we detected at the cyclin D3 mRNA level after 6 and $12 \mathrm{~h}$ may be due to more rapid kinetics and transient induction compared with that of cyclin D1. Moreover, recent data from knockout mice presented by Kushner et al (2005), indicates that cyclin D3 plays a minor role in promoting islet function compared with cyclin D1 and D2. Whereas, cyclin D1 can partially compensate for the absence of cyclin D2, this does not seem to be the case for cyclin D3. However, additional experiments are required to clarify the exact extent and time course of the cyclin D3 regulation we observed in the $\beta$-cells. Forskolin has been shown to augment heregulin-induced cyclin D3 in Schwann cells via the CCAAT/enhancer binding proteinbeta (C/EBPbeta) element indicating a cAMP-dependent regulation of cyclin D3 expression (Fuentealba et al. 2004). This is furthermore in accordance with our findings showing that forskolin was capable of significantly stimulating cyclin D3 expression after 6 and $12 \mathrm{~h}$, respectively. In most cell types the response to CRE is associated with anti-mitogenic effects (Sabbah et al. 1999, Eto 2000, Richards 2001). However, in certain endocrine cell types, cAMP is stimulatory to S-phase progression (Richards 2001). The transcription factors that may potentially interact with the CRE element belong to the cAMP regulatory element binder (CREB)/activating transcription factor (ATF) superfamiliy of transcription factors. The MAPK signalling cascade may be activated by cAMP via guanine nucleotide exchange factors (Leech et al. 2000). MAPK may influence cell proliferation by activation of the transcription factor Elk-1, which binds as a heterodimer to other transcription factors like serum response factor (SRF) involved in the expression of the 
immediate early genes, Fos, Jun and ATF subgroups of transcription factors, that in turn bind as heterodimers to the AP-1 elements of the cyclin D1 or D3 promoter (Dinarello 1996, Lavoie et al. 1996). Activation of the $\mathrm{PI} 3 \mathrm{~K} /$ protein kinase $\mathrm{B}(\mathrm{PKB}) / \mathrm{AKT}$ pathway is linked to cell survival in many systems possibly involving the $\mathrm{PKB} /$ serum and glucocorticoid-inducible kinase substrates ribosomal kinase p70S6K, glycogen synthase kinase-3 (GSK-3), Bcl-2 family member, BAD, and the forkhead transcription factors FKHRL1 and AFX1 (Brunet et al. 1999, Nakamura et al. 2000, Lawlor \& Alessi 2001 Suhara et al. 2002,). The role of this pathway in relation to cell cycle progression is not well understood. However, FKHRL1 has in its un-phosphorylated form been shown to activate genes involved in cell cycle arrest, e.g. p27 kip (Nakamura et al. 2000), and death, e.g. Fas ligand (Suhara et al. 2002). Un-phosphorylated GSK-3 is involved in mediating proteasomal cyclin D1 degradation and has been shown to inhibit cyclin D1 transcription (Diehl et al. 1998). Furthermore, has the PI3K-pathway been linked to SRF-dependent activation of the c-fos promoter, independently of the MAPK pathway (Poser et al. 2000). The identification of the multiple elements and transcription factors potentially involved in incretininduced cyclin D1 and eventually cyclin D3 promoter activation in $\beta$-cells will require thorough analysis of the promoters.

In conclusion, we have identified cyclin D1 as a target gene in $\beta$-cells for incretins. Multiple signalling pathways activated by incretins may contribute to the up-regulation of this gene. Cyclin D3 may be a target gene in $\beta$-cells for incretins as well but this has to be clarified. The finding that $\mathrm{GH} / \mathrm{PRL}$ and incretins in rodents stimulate distinct cyclin D genes may in part explain the additive/synergistic effect of these hormones. Combination of the growth factors may be relevant for in vitro amplification of $\beta$-cells and as potential co-treatment in islet transplantations to maintain graft survival. Furthermore, based on the experienced stimulation of pancreatic cells with GLP-1, GIP and liraglutide we conclude that these hormones have the potential to increase $\beta$-cell regeneration/replication that, if possible to transfer to humans, would have significant impact on long term diabetes treatment.

\section{Acknowledgements}

We want to thank Dagny Jensen and Tina M Olsen for excellent technical assistance and Lotte Bjerre Knudsen and Richard D Carr for helpful discussion. We are indebted to Dr Martin Eilers (University of Marburg, Marburg Germany) for the gift of cyclin D1 promoterreporter construct and Dr Claes B Wollheim (University of Geneva, Geneva, Switzerland) for providing INS-1E cells.

\section{Funding}

Birgitte N Friedrichsen was supported by The Danish Research Academy. Vivian K Gram was supported by Center for Growth and Regeneration (National Agency for Enterprise). Jens $\mathrm{H}$ Nielsen was supported by The Juvenile Diabetes Research Foundation, Danish Center for Stem Cell Research (Danish Medical Research Council), The European Foundation for the Study of Diabetes (EFSD/Johnson\&Johnson), The Danish Diabetes Society, Aase and Ejnar Danielsen's Fund and The Novo Nordisk Foundation. The authors declare that there is no conflict of interest that would prejudice the impartiality of this scientific work.

\section{References}

Asfari M, De W, Postel-Vinay MC \& Czernichow P 1995 Expression and regulation of growth hormone $(\mathrm{GH})$ and prolactin $(\mathrm{PRL})$ receptors in a rat insulin producing cell line (INS-1). Molecular and Cellular Endocrinology 107 209-214.

Bonner-Weir S \& Weir GC 2001 Mechanisms of postnatal $\beta$-cell mass regulation. In Molecular Basis of Pancreas Development and Function, pp 289-297. Eds Habener J \& Hussain MA. Norwell, MA, USA: Kluwer Academic Press.

Bregenholt S, Møldrup A, Blume N, Karlsen AE, Friedrichsen BN, Tornhave D, Knudsen LB \& Petersen JS 2005 The long-acting glucagon-like peptide-1 analogue, liraglutide, inhibits $\beta$-cell apoptosis in vitro. Biochemical and Biophysical Research Communications 350 577-584.

Brubaker PL \& Drucker D 2004 Glucagon-like peptides regulate cell proliferation and apoptosis in the pancreas, gut, and central nervous system. Endocrinology 145 2653-2659.

Brunet A, Bonni A, Zigmond MJ, Lin MZ, Juo P, Hu LS, Anderson MJ, Arden KC, Blenis J \& Greenberg ME 1999 AKT promotes cell survival by phosphorylating and inhibiting a Forkhead transcription factor. Cell 96 857-868.

Brunstedt J, Nielsen JH \& Lernmark Å 1984 Isolation of islets from mice and rats. In Methods in Diabetes Research, pp 245-258. Eds Larner J \& Pohl S. New York, NY, USA: John Wiley and Sons.

Buteau J, Roduit R, Susini S \& Prentki M 1999 Glucagon-like peptide-1 promotes DNA synthesis, activates phosphatidylinositol 3-kinase and increases transcription factor pancreatic and duodenal homeobox gene 1 (PDX-1) DNA binding activity in beta (INS-1)-cells. Diabetologia 42 856-864.

Buteau J, Foisy S, Rhodes CJ, Carpenter L, Biden TJ \& Prentki M 2001 Protein kinase $C \zeta$ activation mediates glucagon-like peptide-1-induced pancreatic $\beta$-cell proliferation. Diabetes $502237-2243$

Delmeire D, Flamez D, Moens K, Hinke SA, Van Schravendijk C, Pipeleers D \& Schuit F 2004 Prior in vitro exposure to GLP-1 with or without GIP can influence subsequent $\beta$-cell responsiveness. Biochemical Pharmacology 68 33-39.

Diehl JA, Cheng M, Roussel MF \& Sherr CJ 1998 Glycogen synthase kinase- 3 beta regulates cyclin D1 proteolysis and subcellular localization. Genes and Development 12 3499-3511.

Dinarello CA 1996 Biologic basis for interleukin-1 in disease. Blood 87 2095-2147.

Eisenbarth GS \& Stegall M 1996 Islet and pancreatic transplantation - autoimmunity and alloimmunity. New England Journal of Medicine 335 888-890.

Eto I 2000 Molecular cloning and sequence analysis of the promoter region of mouse cyclin D1 gene: implication in phorbol esterinduced tumour promotion. Cell Proliferation 33 167-187. 
Fantl V, Stamp G, Andrews A, Rosewell I \& Dickson C 1995 Mice lacking cyclin D1 are small and show defects in eye and mammary gland development. Genes and Development 9 2364-2372.

Farilla L, Bulotta A, Hirshberg B, Li-Calzi S, Khoury N, Noushmehr H, Bertolotto C, Di Mario U, Harlan DM \& Perfetti R 2003 Glucagon-like peptide 1 inhibits cell apoptosis and improves glucose responsiveness of freshly isolated human islets. Endocrinology 144 5149-5158.

Fehmann HC \& Habener JF 1992 Insulinotropic hormone glucagon-like peptide-I(7-37) stimulation of proinsulin gene expression and proinsulin biosynthesis in insulinoma beta TC-1 cells. Endocrinology 130 159-166.

Friedrichsen BN, Galsgaard ED, Nielsen JH \& Møldrup A 2001 Growth hormone- and prolactin-induced proliferation of insulinoma cells, INS-1 depends on activation of STAT5 (signal transducer and activator of transcription 5). Molecular Endocrinology 15 136-148.

Friedrichsen BN, Richter HE, Hansen JA, Rhodes CJ, Nielsen JH, Billestrup N \& Møldrup A 2003 Signal transducer and activator of transcription 5 activation is sufficient to drive transcriptional induction of cyclin D2 gene and proliferation of rat pancreatic $\beta$-cells. Molecular Endocrinology 17 945-958.

Frödin M, Sekine N, Roche E, Filloux C, Prentki M, Wollheim CB \& Vanobberghen E 1995 Glucose, other secretagogues, and nerve growth-factor stimulate mitogen- activated protein-kinase in the insulin-secreting $\beta$-cell line, INS-1. Journal of Biological Chemistry $2707882-7889$.

Fuentealba L, Schworer C, Schroering A, Rahmatullah M \& Carey DJ 2004 Heregulin and forskolin-induced cyclin D3 expression in Schwann cells: role of a CCAAT promoter element and CCAAT enhancer binding protein. Glia 45 238-248.

Galsgaard ED, Nielsen JH \& Møldrup A 1999 Regulation of prolactin receptor (PRLR) gene expression in insulin-producing cells. Prolactin and growth hormone activate one of the rat PRLR gene promoters via STAT5a and STAT5b. Journal of Biological Chemistry 274 18686-18692.

Garrett MA 2001 Cell cycle control and cancer. Current Science 81 515-522.

Holst JJ 1999 Glucagon-like peptide-1, a gastrointestinal hormone with a pharmaceutical potential. Current Medicinal Chemistry 6 1005-1017.

Holst JJ \& Gromada J 2004 Role of incretin hormones in the regulation of insulin secretion in diabetic and nondiabetc humans. American Journal of Physiology Endocrinology and Metabolism 287 E199-E206.

Holst JJ, Gromada J \& Nauck MA 1997 The pathogenesis of NIDDM involves a defective expression of the GIP receptor. Diabetologia 40 984-986.

Hui H, Nourparvar A, Zhao X \& Perfetti R 2003 Glucagon-like peptide-1 inhibits apoptosis of insulin-secreting cells via a cyclic $5^{\prime}$-adenosine monophosphate-dependent protein kinase A- and a phosphatidylinositol 3-kinase-dependent pathway. Endocrinology 144 1444-1455.

Hussain MA, Daniel PB \& Habener JF 2000 Glucagon stimulates expression of the inducible cAMP early repressor and suppresses insulin gene expression in pancreatic $\beta$-cells. Diabetes 49 1681-1690.

Kushner JA, Ciemerych MA, Sicinska E, Wartschow LM, Teta M, Long SY, Sicinski P \& White MF 2005 Cyclins D2 and D1 are essential for postnatal pancreatic $\beta$ cell growth. Molecular and Cellular Biology 25 3752-3762.

Lahti JM, Li H \& Kidd VJ 1997 Elimination of cyclin D1 in vertebrate cells leads to an altered cell cycle phenotype, which is rescued by overexpression of murine cyclins D1, D2, or D3 but not by a mutant cyclin D1. Journal of Biological Chemistry 272 10859-10869.
Lania L, Majello B \& Napolitano G 1999 Transcriptional control by cell-cycle regulators: a review. Journal of Cellular Physiology 179 134-141.

Lavoie JN, L'Allemain G, Brunet A, Müller R \& Pouyssegur J 1996 Cyclin D1 expression is regulated positively by the p42/p44 MAPK and negatively by the p38/HOGMAPK pathway. Journal of Biological Chemistry 271 20608-20616.

Lawlor MA \& Alessi DR 2001 PKB/AKT: A key mediator of cell proliferation, survival and insulin responses? Journal of Cell Science 114 2903-2910.

Leech CA, Holz GG, Chepurny O \& Habener JF 2000 Expression of cAMP-regulated guanine nucleotide exchange factors in pancreatic $\beta$-cells. Biochemical and Biophysical Research Communications 278 44-47.

McDonald ER \& El Deiry WS 2000 Cell cycle control as a basis for cancer drug development (Review). International Journal of Oncology $16871-886$.

Moens K, Heimberg H, Flamez D, Huypens P, Quartier E, Ling Z, Pipeleers D, Gremlich S, Thorens B \& Schuit F 1996 Expression and functional activity of glucagon, glucagon-like peptide I, and glucose-dependent insulinotropic peptide receptors in rat pancreatic islet cells. Diabetes 45 257-261.

Moens K, Flamez D, Van Schravendijk C, Ling Z, Pipeleers D \& Schuit F 1998 Dual glucagon recognition by pancreatic $\beta$-cells via glucagon and glucagon-like peptide 1 receptors. Diabetes 47 66-72.

Nakamura N, Ramaswamy S, Vazquez F, Signoretti S, Loda M \& Sellers WR 2000 Forkhead Transcription factors are critical effectors of cell death and cell cycle arrest downstream of PTEN. Molecular and Cellular Biology 20 8969-8982.

Nielsen JH, Linde S, Welinder BS, Billestrup N \& Madsen OD 1989 Growth hormone is a growth factor for the differentiated pancreatic beta-cell. Molecular Endocrinology 3 165-173.

Nielsen JH, Galsgaard ED, Møldrup A, Friedrichsen BN, Billestrup N, Hansen JA, Lee YC \& Carlsson C 2001 Regulation of $\beta$-cell mass by hormones and growth factors. Diabetes $\mathbf{5 0}$ S25-S29.

Poser S, Impey S, Trinh K, Xia ZG \& Storm DR 2000 SRF-dependent gene expression is required for PI3-kinaseregulated cell proliferation. EMBO Journal 19 4955-4966.

Poser J, Foisy S, Joly E \& Prentki M 2003 Glucagon-like peptide 1 induces pancreatic $\beta$-cell proliferation via transactivation of the epidermal growth factor receptor. Diabetes 52 124-132.

Preitner F, Ibberson M, Franklin I, Binnert C, Pende M, Gjinovci A, Hansotia T, Drucker DJ, Wollheim C, Burcelin R et al. 2004 Gluco-oncretins control insulin secretion at multiple levels as revealed in mice lacking GLP-1 and GIP receptors. Journal of Clinical Investigations 113 635-645.

Rane SG, Dubus P, Mettus RV, Galbreath EJ, Boden G, Reddy EP \& Barbacid M 1999 Loss of Cdk4 expression causes insulindeficient diabetes and $\mathrm{Cdk} 4$ activation results in beta-islet cell hyperplasia. Nature Genetics 22 44-54.

Reetz A, Solimena M, Matteoli M, Folli F, Takei K \& De Camilli P 1991 GABA and pancreatic $\beta$-cells. EMBO Journal 10 1275-1284.

Richards JS 2001 New signaling pathways for hormones and cyclic adenosine $3^{\prime *} ; 5^{\prime}$ monophosphate action in endocrine cells. Molecular Endocrinology 15 209-218.

Sabbah M, Courilleau D, Mester J \& Redeuilh G 1999 Estrogen induction of the cyclin D1 promoter: Involvement of a cAMP response-like element. PNAS 96 11217-11222.

Sicinski P, Donaher JL, Geng Y, Parker SB, Gardner H, Park MY, Robker RL, Richards JS, McGinnis LK, Biggers JD et al. 1996 Cyclin D2 is an FSH-responsive gene involved in gonadal cell proliferation and oncogenesis. Nature 384 470-474.

Skoglund G, Hussain MA \& Holz GG 2000 Glucagon-like peptide 1 stimulates insulin gene promoter activity by protein kinase A-independent activation of the rat insulin I gene cAMP response element. Diabetes 49 1156-1164.

Stoffers DA, Kieffer TJ, Hussain MA, Drucker DJ, Bonner-Weir S, Habener JF \& Egan JM 2000 Insulinotropic glucagon-like peptide 
1 agonists stimulate expression of homeodomain protein IDX-1 and increase islet size in mouse pancreas. Diabetes 49 741-748.

Suhara T, Kim HS, Kirshenbaum LA \& Walsh K 2002 Suppression of AKT signaling induces Fas ligand expression: Involvement of caspase and jun kinase activation in AKT- mediated Fas ligand regulation. Molecular and Cellular Biology 22 680-691.

Trümper A, Trümper K, Trusheim H, Arnold R, Göke B \& Hörsch D 2001 Glucose-dependent insulinotropic polypeptide is a growth factor for beta (INS-1) cells by pleiotropic signaling. Molecular Endocrinology 15 1559-1570.

Urusova IA, Farilla L, Hui H, D'Amico E \& Perfetti R 2004 GLP-1 inhibition of pancreatic islet cell apoptosis. Trends in Endocrinology and Metabolism 15 27-33.
Wang Z, Sicinski P, Weinberg RA, Zhang Y \& Ravid K 1996 Characterization of the mouse cyclin D3 gene: exon/intron organization and promoter activity. Genomics 35 156-163.

Xu G, Stoffers DA, Habener JF \& Bonner-Weir S 1999 Exendin-4 stimulates both $\beta$-cell replication and neogenesis, resulting in increased $\beta$-cell mass and improved glucose tolerance in diabetic rats. Diabetes 48 2270-2276.

Received 1 December 2005 Accepted 11 December 2005 